BMJ Open

Diabetes

Research

\& Care

\title{
Air pollution and gestational diabetes mellitus: evidence from cohort studies
}

\author{
Xingyao Tang, ${ }^{1}$ Jian-Bo Zhou (D) , ${ }^{2}$ Fuqiang Luo, ${ }^{1}$ Yipeng Han, ${ }^{1}$ Yoriko Heianza, ${ }^{3}$ \\ Marly Augusto Cardoso, ${ }^{4} \mathrm{Lu} \mathrm{Qi}^{3}$
}

To cite: Tang X, Zhou J-B, Luo $\mathrm{F}$, et al. Air pollution and gestational diabetes mellitus: evidence from cohort studies. BMJ Open Diab Res Care 2020;8:e000937. doi:10.1136/ bmjdrc-2019-000937

- Additional material is published online only. To view please visit the journal online (http://dx.doi.org/10.1136/ bmjdrc-2019-000937).

$\mathrm{XT}$ and J-BZ contributed equally.

Received 30 September 2019 Revised 7 January 2020 Accepted 14 January 2020

A) Check for updates

(C) Author(s) (or their employer(s)) 2020. Re-use permitted under CC BY. Published by BMJ.

${ }^{1}$ Department of Education, Beijing Tongren Hospital, Beijing, China

${ }^{2}$ Department of Endocrinology, Beijing Tongren Hospital, Beijing, China

${ }^{3}$ Department of Epidemiology, Tulane University School of Public Health and Tropical Medicine, New Orleans, Louisiana, USA

${ }^{4}$ Department of Nutrition, School of Public Health, University of São Paulo, São Paulo, Brazil

Correspondence to Dr Jian-Bo Zhou;

jbzhou@ccmu.edu.cn

\section{ABSTRACT}

Exposure to different air pollutants has been linked to type 2 diabetes mellitus, but the evidence for the association between air pollutants and gestational diabetes mellitus (GDM) has not been systematically evaluated. We systematically retrieved relevant studies from PubMed, Embase, and the Web of Science, and performed stratified analyses and regression analyses. Thirteen studies were analyzed, comprising 1547154 individuals from nine retrospective studies, three prospective studies, and one case-control study. Increased exposure to particulate matter $\leq 2.5 \mu \mathrm{m}$ in diameter $\left(\mathrm{PM}_{2.5}\right)$ was not associated with the increased risk of GDM (adjusted OR $1.03,95 \% \mathrm{Cl}$ 0.99 to 1.06). However, subgroup analysis showed positive correlation of $\mathrm{PM}_{2.5}$ exposure in the second trimester with an increased risk of GDM (combined OR 1.07, 95\% Cl 1.00 to 1.13). Among pollutants other than $\mathrm{PM}_{2.5}$, significant association between GDM and nitrogen dioxide $\left(\mathrm{NO}_{2}\right)(\mathrm{OR}$ $1.05,95 \% \mathrm{Cl} 1.01$ to 1.10), nitrogen oxide ( $\mathrm{NO}_{\mathrm{x}}$ ) (OR 1.03, $95 \% \mathrm{Cl} 1.01$ to 1.05$)$, and sulfur dioxide $\left(\mathrm{SO}_{2}\right)$ (OR 1.09, $95 \% \mathrm{Cl} 1.03$ to 1.15 ) was noted. There was no significant association between exposure to black carbon or ozone or carbon monoxide or particulate matter $\leq 10 \mu \mathrm{m}$ in diameter and GDM. Thus, systematic review of existing evidence demonstrated association of exposure to $\mathrm{NO}_{2}, \mathrm{NO}_{x}$, and $\mathrm{SO}_{2}$, and the second trimester exposure of $\mathrm{PM}_{2.5}$ with the increased risk of GDM. Caution may be exercised while deriving conclusions from existing evidence base because of the limited number and the observational nature of studies.

\section{INTRODUCTION}

Diabetes mellitus (DM) is a major cause of concern because of its increasing prevalence that has led to a consequential increase in the microvascular as well as macrovascular complications. ${ }^{1}$ Gestational diabetes mellitus (GDM) is a special type of DM characterized by any degree of glucose intolerance with onset, or first recognition during the pregnancy. ${ }^{2}$ It complicates $2 \%-6 \%$ of pregnancies worldwide, and as many as $10 \%-20 \%$ of high-risk pregnancy (body mass index (BMI) $>30 \mathrm{~kg} / \mathrm{m}^{2}$; previous macrosomic baby weighing $\geq 4.5 \mathrm{~kg}$; personal history of gestational diabetes; family history of gestational diabetes; family history of diabetes) populations. ${ }^{3}$ GDM increases the affected woman's risk of pre-eclampsia, asymptomatic bacteriuria, pyelonephritis, and cesarean delivery. ${ }^{4}$ Biological factors, such as older age, obesity, and family history, are known to increase the individual's risk of GDM. However, the exact role and effects of environmental agents in GDM remain unknown.

Air pollution is one of the environmental health risks for GDM. ${ }^{5}$ Many studies have shown that air pollution exposure is related to impaired glucose homeostasis in susceptible populations. ${ }^{6-8}$ Association between air pollution and risk of type 2 diabetes mellitus has been reviewed. ${ }^{9}$ The underlying mechanisms could include endothelial dysfunction, dysregulation of the visceral adipose tissue through inflammation, hepatic insulin resistance, and alterations in autonomic tone that may increase peripheral insulin resistance. ${ }^{10}$ Type 2 diabetes and GDM share common risk factors, and both are characterized by insulin resistance and impaired insulin secretion. ${ }^{11}$

The relationship between air pollutants and GDM has not been studied systematically though a number of related studies have been published. ${ }^{12-24}$ To the best of our knowledge, thus far, there is no available accumulated evidence on their relationship. We therefore systematically identified, and reviewed the epidemiological evidence on the association between air pollutants and GDM.

\section{MATERIALS AND METHODS \\ Study inclusion}

The PubMed and Embase databases and Web of Science were searched for relevant studies published until August 2019. Terms used in the search included 'air pollution', 'air pollutant', 'particulate matter', ' $\mathrm{PM}_{25}$ ', ' $\mathrm{PM}_{10}$, ' 'nitrogen dioxide', ' $\mathrm{O}_{3}$ ', ' $\mathrm{NO}_{2}$ ', ' $\mathrm{NO}_{\mathrm{x}}$ ', 'SO ', 'ozone', 'soot', 'smog', 'gestational diabetes', 'gestational diabetes mellitus', 'GDM', 'pregnancy diabetes mellitus', 'pregnancy diabetes', and 'pregnancy glucose tolerance' in combination. The search strategy was further supplemented 
by inspecting the references of the included articles. Two reviewers (XT and $\mathrm{YiH}$ ) completed the screening independently, and any discrepancies were resolved by discussion. This report was conducted according to the Meta-analysis Of Observational Studies in Epidemi$\operatorname{ology}^{25}$ and the Preferred Reporting Items for Systematic Reviews and Meta-Analyse ${ }^{26}$ guidelines. Because of reanalysis of published data, ethical approval was not needed for this study.

\section{Inclusion and exclusion criteria}

Studies were considered for inclusion based on the following criteria: (1) the study was an original article published in English; (2) it defined air pollution and GDM status clearly; (3) it measured the outdoor air pollution (ambient, including traffic related); (4) it used physical diagnosis of GDM, if diabetes is diagnosed in the first trimester or early second trimester with the standard diagnostic criteria of a hemoglobin A1c of $6.5 \%$ or higher, a fasting plasma glucose of $126 \mathrm{mg} / \mathrm{dL}$ or higher, or a 2-hour glucose of $200 \mathrm{mg} /$ $\mathrm{dL}$ or higher on a $75 \mathrm{~g}$ oral glucose tolerance test, it was considered gestational diabetes ${ }^{27}$; and (5) it provided quantitative measures of association between air pollutants and GDM, and their 95\% CIs. Exclusion criteria were as follows: (1) the publication was a review, case report, animal study or letter to the editor, (2) the articles did not clearly define the clinical outcomes, (3) the authors could not provide valid solicited data, and (4) the studies only examined whether the diabetes status would modify the association between air pollution and health outcomes.

For the meta-analysis, only cohort studies about particulate matter $\leq 2.5 \mu \mathrm{m}$ in diameter $\left(\mathrm{PM}_{2.5}\right)$, ozone $\left(\mathrm{O}_{3}\right)$, sulfur dioxide $\left(\mathrm{SO}_{2}\right)$, black carbon $(\mathrm{BC})$, nitrogen dioxide $\left(\mathrm{NO}_{2}\right)$, nitrogen oxide $\left(\mathrm{NO}_{\mathrm{x}}\right)$, particulate matter $\leq 10 \mu \mathrm{m}$ in diameter $\left(\mathrm{PM}_{10}\right)$, and carbon monoxide $(\mathrm{CO})$ were included. We included all studies that quantified these air pollutants as 'per $\ldots \mu \mathrm{g} / \mathrm{m}^{3}$ ' or 'ppb' or 'ppm'.

\section{Data extraction and quality assessment}

Two investigators (XT and $\mathrm{YiH}$ ) independently extracted data from the enrolled studies, using a standard form that included publication year, country of origin, testing method, number of cases, control type, and cutoff value. Two investigators independently assessed the risk of bias for the enrolled studies (XT and FL) using the Newcastle-Ottawa Quality Assessment Scale (NOS) criteria. ${ }^{28}$ Three factors were considered while scoring the quality of included studies: (1) selection, including representativeness of the exposed cohort, selection of the non-exposed cohort, ascertainment of exposure, and the demonstration that at the initiation of the study the outcome of interest was not present; (2) comparability, assessed on the basis of study design and analysis, and whether any confounding variables were adjusted for; and (3) outcome, based on the follow-up period and adequacy of cohorts, and ascertained by independent blind assessment, record linkage, or self-report. We rated the quality of the studies by awarding stars in each domain following the guidelines of NOS. If there was a disagreement, the investigators discussed the research with the other authors to arrive at a consensus.

\section{Statistical analysis}

Heterogeneity and variance between the enrolled studies was evaluated using $\mathrm{I}^{2}$ metric, and $\mathrm{Tau}^{2}$ respectively. Random effects models were performed to synthesize the association between different air pollutants and GDM in case of $\mathrm{I}^{2}>50 \%$. Random effects models give more weight to smaller studies and have typically wider CIs because the total effect is the average value of the real effect of each study that focuses on the studies with large samples, and pays attention to all included studies in order to balance the effect of each study. Fixed effects models were chosen in case of $\mathrm{I}^{2} \leq 50 \%$. ORs as the measure of association were pooled across all studies. If studies reported both unadjusted and covariate-adjusted ORs, we included the latter. When risk ratios and incidence ORs were reported, we directly considered them as ORs. For studies providing different methods of air pollution exposure assessments, we chose the results using spatiotemporal models. We used estimates of association and their SEs reported as 'per $5 \mu \mathrm{g} / \mathrm{m}^{3}$, of exposure in $\mathrm{PM}_{25}$, "per $10 \mu \mathrm{g} / \mathrm{m}^{3}$, of exposure in $\mathrm{PM}_{10}$, 'per $0.5 \mu \mathrm{g} / \mathrm{m}^{3}$, in $\mathrm{BC}$, 'per 5 ppb' in $\mathrm{O}_{3}$ and $\mathrm{SO}_{2}$, 'per 10 ppb' in $\mathrm{NO}_{2}$ and $\mathrm{NO}_{\mathrm{x}}$, and 'per $0.1 \mathrm{ppm}$ ' in CO. We converted other reported quantities or units where necessary. Potential publication bias was evaluated by Egger's asymmetry test. ${ }^{29} \mathrm{P}$ values were two tailed, and $\mathrm{p}<0.05$ was considered statistically significant. Sensitivity analyses were conducted when including at least five data points. The statistical analyses were performed with STATA V.12.0 (StataCorp, College Station, TX, USA).

\section{RESULTS}

\section{Study selection and study characteristics}

As per our search strategy, we identified 852 potentially relevant records, of which 229 were duplicate, and thus excluded. The remaining 623 manuscripts were subject to title and abstract screening. Further, 525 publications were removed as they were reviews, letters or conference abstracts or unrelated studies. Therefore, 98 articles were eligible for full-text review and data assessment (figure 1). Finally, 85 articles were excluded for other reasons (animal studies $(n=3)$, unable to extract information $(n=50)$, and lack of full publication $(\mathrm{n}=32)$ ). The remaining 13 studies were enrolled in the meta-analysis ${ }^{12-24}$ out of which three were prospective cohort studies, ${ }^{13} 1922$ nine were retrospective cohort studies ${ }^{12}$ 14-18 202324 and one was a casecontrol study. ${ }^{21}$ Seven studies were on $\mathrm{PM}_{2,5}{ }^{12-15} 202324$ four studies were on $\mathrm{O}_{3},{ }^{15} 182024$ three studies were on $\mathrm{PM}_{10}{ }^{18} 2024$ while two studies on each of the following 


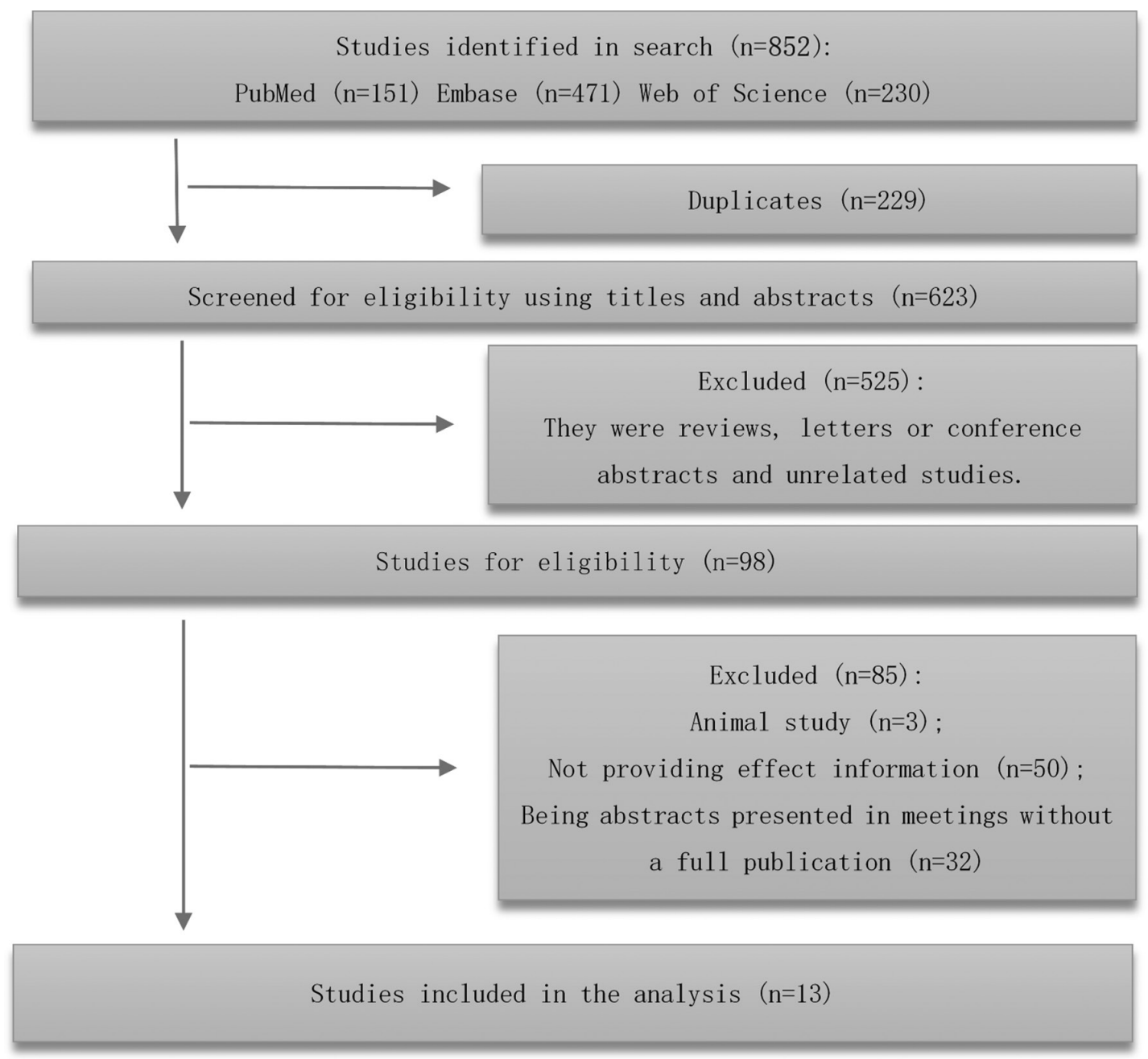

Figure 1 Literature search and selection process.

pollutants were included: $\mathrm{SO}_{2}{ }^{18}{ }^{20} ; \mathrm{NO}_{\mathrm{x}}{ }^{18}{ }^{20}$; $\mathrm{CO} ; \mathrm{BC}^{12}{ }^{13}$; and $\mathrm{NO}_{2} \cdot{ }^{2324}$ Tables 1 and 2 provide an overview of the 13 enrolled studies. Online supplementary table S1 summarizes the data reported in these studies as synthesized in meta-analyses.

\section{Quality assessment}

Quality assessment using the NOS evaluation tool resulted in high ratings for all the 13 studies (score 7 or 8) (online supplementary table S2).

\section{Meta-analysis results}

There were 13 sets of data on $\mathrm{PM}_{2.5}\left(\mathrm{Q}=106.07, \mathrm{I}^{2}=88.7 \%\right.$, $\mathrm{p}=0.000), 8$ sets of data on $\mathrm{O}_{3}{ }^{2.5}\left(\mathrm{Q}=344.11, \mathrm{I}^{2}=98.0 \%\right.$, $\mathrm{p}<0.001), 6$ sets of data on $\mathrm{PM}_{10}\left(\mathrm{Q}=8.91, \mathrm{I}^{2}=43.9 \%\right.$, $\mathrm{p}=0.113), 4$ sets of data on each of the following: $\mathrm{NO}_{2}$ $\left(\mathrm{Q}=17.50, \mathrm{I}^{2}=82.9 \%, \mathrm{p}=0.001\right), \mathrm{SO}_{2}\left(\mathrm{Q}=4.26, \mathrm{I}^{2}=29.6 \%\right.$, $\mathrm{p}=0.234), \mathrm{CO}\left(\mathrm{Q}=7.08, \mathrm{I}^{2}=57.7 \%, \mathrm{p}=0.069\right), \mathrm{NO}_{\mathrm{x}}(\mathrm{Q}=7.12$, $\left.\mathrm{I}^{2}=57.9 \%, \mathrm{p}=0.068\right)$, and 3 sets of data on $\mathrm{BC}(\mathrm{Q}=0.34$, $\left.\mathrm{I}^{2}=0.0 \%, \mathrm{p}=0.562\right)$. As per the heterogeneity, the random effects model was selected for analysis of $\mathrm{PM}_{2.5}, \mathrm{O}_{3}, \mathrm{NO}_{2}$, $\mathrm{CO}$, and $\mathrm{NO}_{\mathrm{x}}$, while the fixed effects model was chosen for $\mathrm{SO}_{2}, \mathrm{PM}_{10}$, and $\mathrm{BC}$.
The statistically significant pooled effect value was absent in the relationship between $\mathrm{PM}_{2.5}$ and GDM ( $\mathrm{Z}$ test, $\mathrm{Z}=1.55, \mathrm{p}=0.122$, the combined OR $1.06,95 \% \mathrm{CI}$ 0.99 to 1.03$)$. We further performed the subgroup analysis for $\mathrm{PM}_{2.5}$ exposure in the different periods, including the pre-pregnancy, the first trimester and the second trimester. Subgroup analysis revealed that the above non-significant association persisted in both the prepregnancy and the first trimester (the overall OR of 1.00 (95\% CI 0.95 to 1.06 ) and 1.01 (95\% CI 0.96 to 1.07 ), respectively). However, in the second trimester, exposure to $\mathrm{PM}_{2.5}$ was associated with the increased risk of GDM $(\mathrm{Z}=2.11, \mathrm{p}=0.035$, the overall $\mathrm{OR}=1.07,95 \% \mathrm{CI} 1.00$ to 1.13) (figure 2A).

The significant relationship of exposure to $\mathrm{SO}_{2}$ with increased risk of GDM was noted $(\mathrm{Z}=3.83, \mathrm{p}<0.001$, the overall $\mathrm{OR}=1.08,95 \%$ CI 1.04 to 1.12 ). In the subgroup analysis, the positive association was consistently observed in the pre-pregnancy, the first trimester, and the second trimester (the overall OR of 1.08 (95\% CI 1.02 to 1.14 ), 1.07 (95\% CI 1.01 to 1.13 ), and 1.34 (95\% CI 1.01 to 1.78 ), respectively) (figure $2 \mathrm{~B}$ ). 


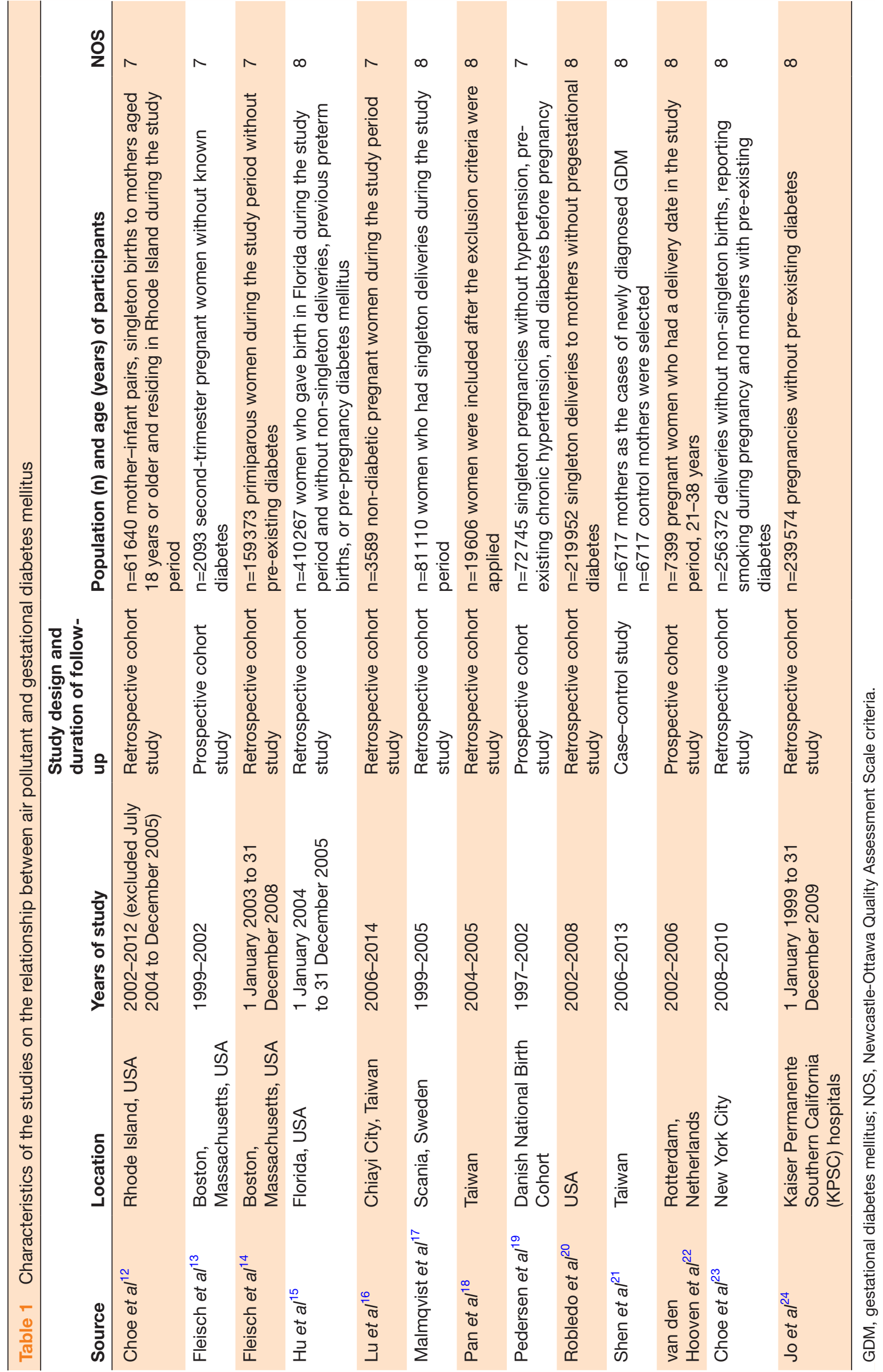



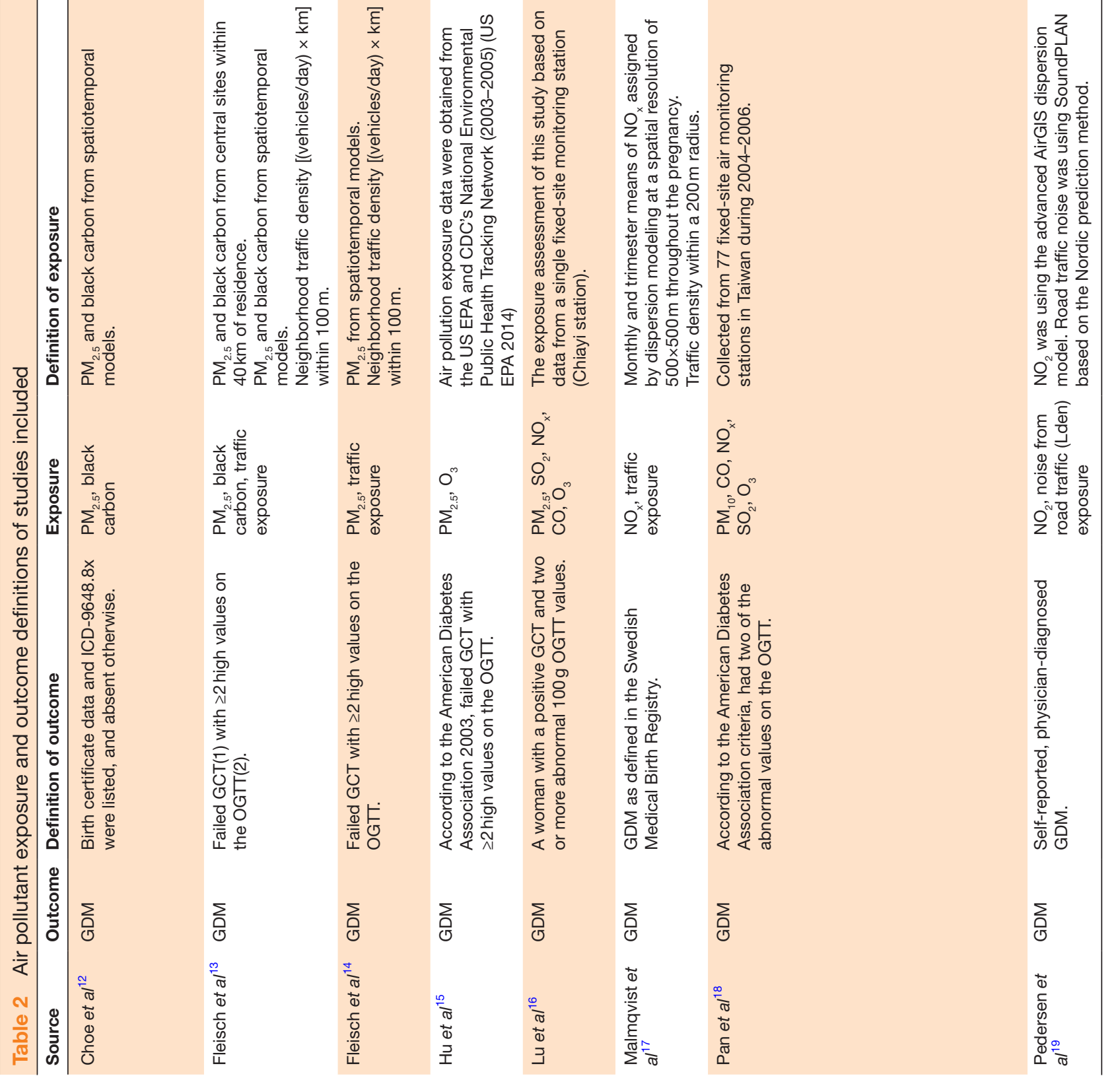

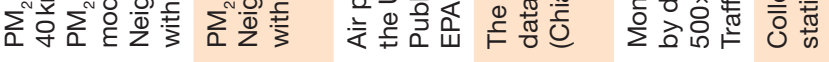

号尊 $\quad 0 \quad 2^{x}$

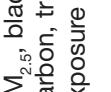

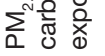
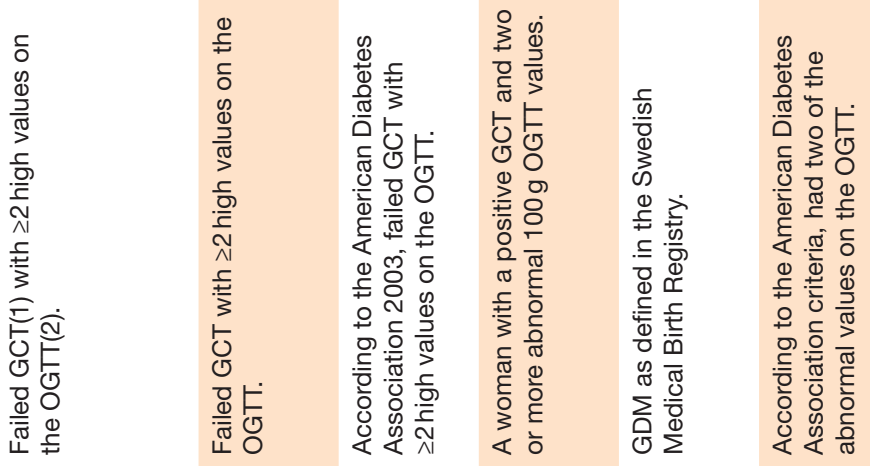

잉

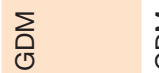

ฮั่

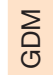

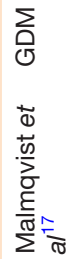

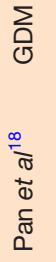

$\alpha$ ช 


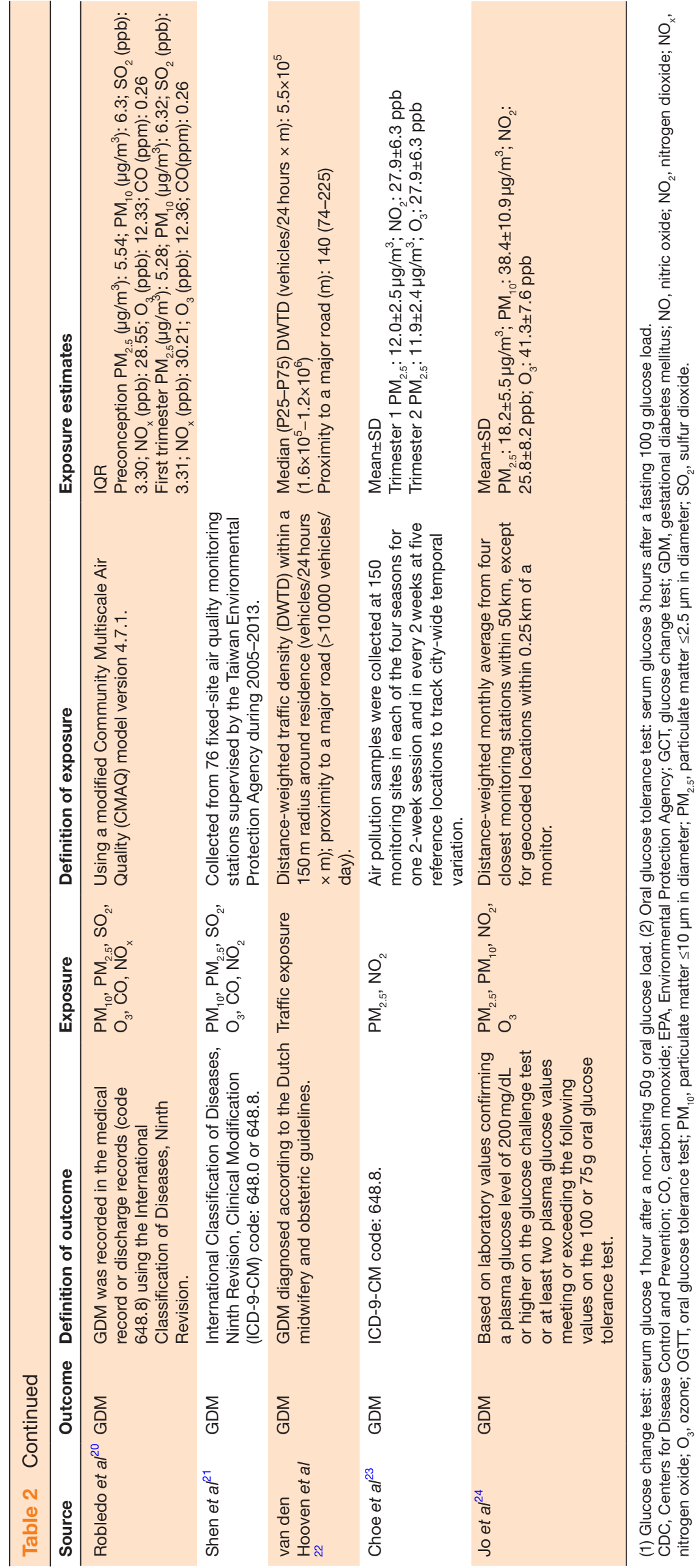


A.

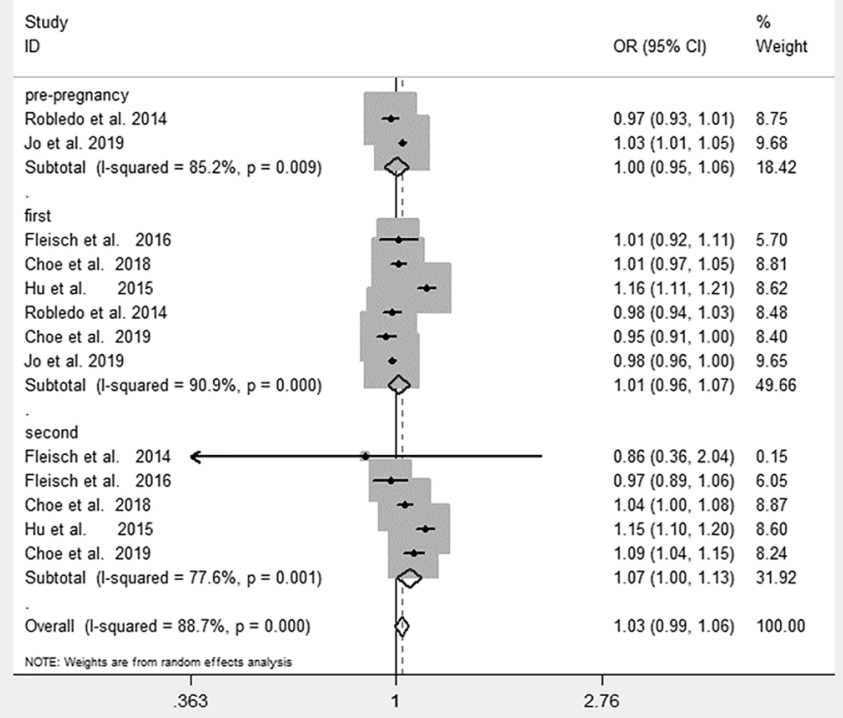

C.

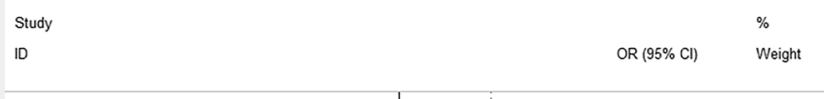

pre-pregnancy

Jo et al. 2019

Subtotal (l-squared $=\%, p=$ )

first

Choe et al. 2019

Jo et al. 2019

Subtotal (l-squared $=45.6 \%, p=0.175)$

second

Choe et al. 2019

Subtotal (1-squared $=\%, p=$ )

Overall (l-squared $=82.9 \%, p=0.001)$

NOTE: Weights sae from ransom effects anaysis

.889

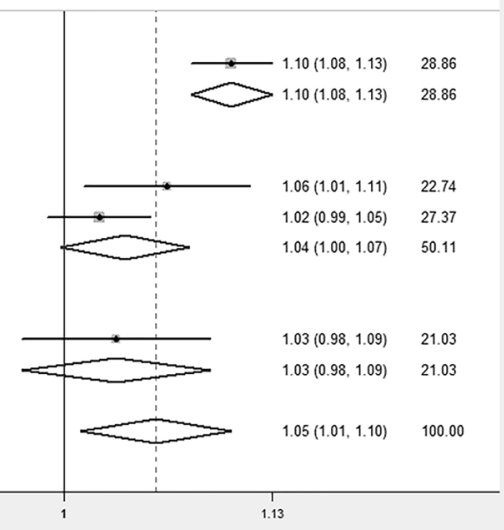

B.

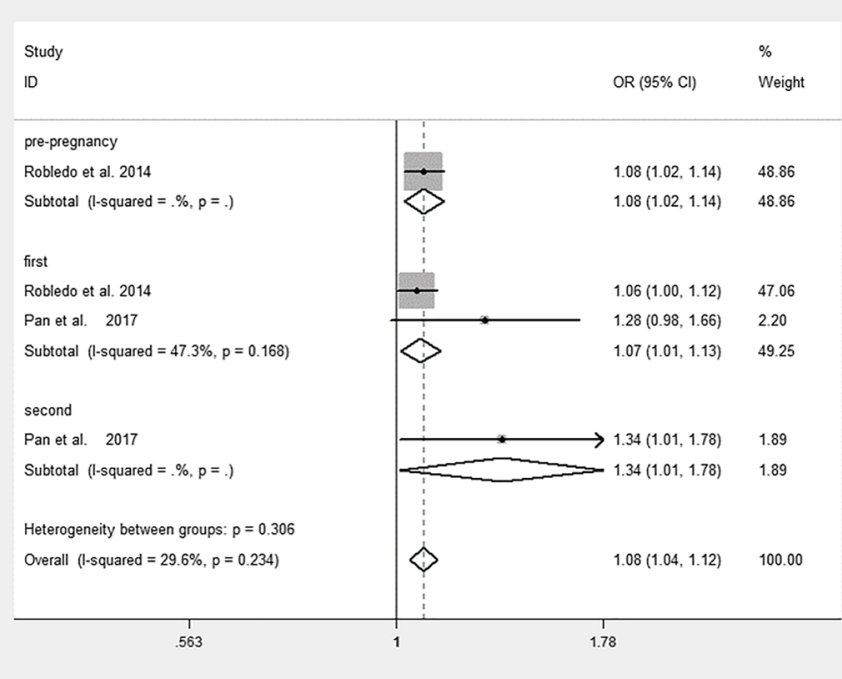

D.

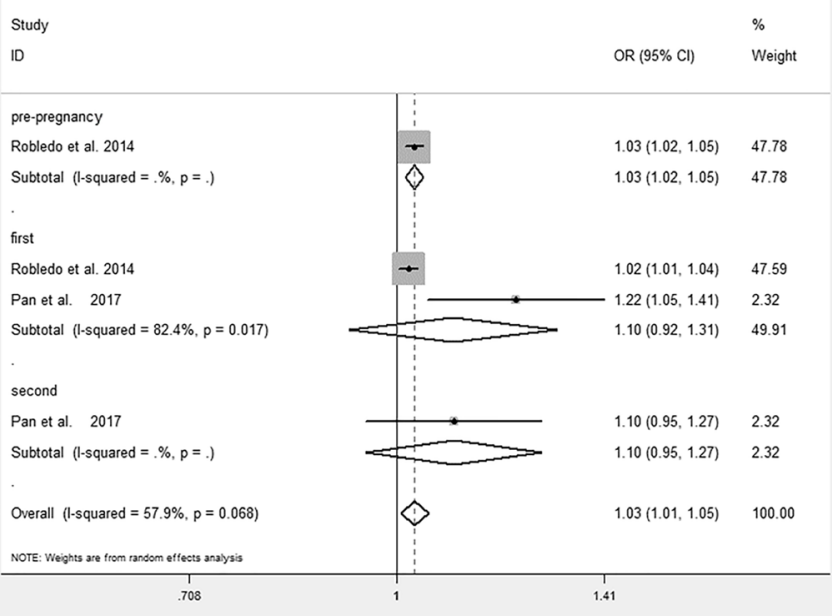

Figure 2 Forest plot and pooled estimates of the association between exposure to A) particulate matter $\leq 2.5 \mu \mathrm{m}$ in diameter $\left(\mathrm{PM}_{2.5}\right)$, B) sulfur dioxide $\left.\left(\mathrm{SO}_{2}\right), \mathrm{C}\right)$ nitrogen dioxide $\left(\mathrm{NO}_{2}\right)$ and $\left.\mathrm{D}\right)$ nitrogen oxide $\left(\mathrm{NO}_{\mathrm{x}}\right)$ with risk of gestational diabetes mellitus (GDM). Pre-pregnancy, the exposure to PM2.5 was measured before pregnancy; first, the exposure to PM2.5 was measured during the first trimester; second, the exposure to PM2.5 was measured during the second trimester. GDM, gestational diabetes mellitus; $\mathrm{NO}_{2}$, nitrogen dioxide; $\mathrm{NO}_{x}$, nitrogen oxides; OR, odds ratio; PM2.5, particulate matter $\leq 2.5 \mu \mathrm{m}$ in diameter; $\mathrm{SO} 2$, sulfurdioxide.

There was a statistically significant correlation between exposure to $\mathrm{NO}_{2}$ and the increased risk of GDM $(\mathrm{Z}=2.40$, $\mathrm{p}=0.016$, the overall $\mathrm{OR}=1.05,95 \%$ CI 1.01 to 1.10$)$. In the subgroup analysis, the same correlation was persistent in the pre-pregnancy and the first trimester subgroups (pooled OR=1.10 (95\% CI 1.08 to 1.13) and 1.04 (95\% CI 1.00 to 1.07), respectively) (figure 2C).

Exposure to $\mathrm{NO}_{\mathrm{x}}$ was also related to an increased risk of GDM ( $\mathrm{Z}=2.62, \mathrm{p}=0.009$, the overall $\mathrm{OR}=1.03,95 \% \mathrm{CI}$ 1.01 to 1.06$)$. In the pre-pregnancy subgroup, a positive association was noted between the exposure to $\mathrm{NO}_{\mathrm{x}}$ and GDM $(\mathrm{Z}=3.96, \mathrm{p}=0.000$, the overall $\mathrm{OR}=1.03,95 \%$ CI 1.02 to 1.05$)$. However, in the first trimester, and the second trimester subgroups, the association was missing (first trimester, $\mathrm{Z}=1.06, \mathrm{p}=0.287$, the overall $\mathrm{OR}=1.10,95 \% \mathrm{CI}$
0.92 to 1.31 and second trimester, $\mathrm{Z}=1.28, \mathrm{p}=0.202$, the overall $\mathrm{OR}=1.10,95 \% \mathrm{CI} 0.95$ to 1.27 ) (figure 2D).

The non-significant relationship between $\mathrm{BC}$ and GDM was obtained $(\mathrm{Z}=1.13, \mathrm{p}=0.257$, the overall $\mathrm{OR}=1.02$, $95 \%$ CI 0.99 to 1.05 ) (online supplementary figure $\mathrm{S} 1 \mathrm{~A})$. Similar results were observed in $\mathrm{CO}, \mathrm{O}_{3}$, and $\mathrm{PM}_{10}$ ( $\mathrm{Z}=0.88, \mathrm{p}=0.380$, the overall $\mathrm{OR}=1.01,95 \% \mathrm{CI} 0.99$ to 1.03; $\mathrm{Z}=0.69, \mathrm{p}=0.489$, the overall $\mathrm{OR}=1.01,95 \%$ CI 0.98 to $1.04 ; \mathrm{Z}=0.53, \mathrm{p}=0.595$, the overall $\mathrm{OR}=1.00,95 \% \mathrm{CI}$ 0.99 to 1.01 , respectively) (online supplementary figure S1B,C).

\section{Sensitivity analysis}

Sensitivity analyses of $\mathrm{PM}_{2.5}, \mathrm{PM}_{10}$, and $\mathrm{O}_{3}$ were performed through single elimination of studies. The sensitivity 
analyses between the exposures to $\mathrm{PM}_{2.5}, \mathrm{PM}_{10}$, and $\mathrm{O}_{3}$ and the risk of GDM indicated no significant change in results.

\section{Publication bias}

According to the Cochrane Handbook version 5.1.0, ${ }^{30}$ as a rule of thumb, tests for funnel plot asymmetry should be used only when there are not too few research included in the meta-analysis, because when there are fewer studies, the power of the tests is too low to distinguish chance from real asymmetry. Therefore, we restricted this analysis to $\mathrm{PM}_{2.5}, \mathrm{O}_{3}$, and $\mathrm{PM}_{10}$, no significant bias exists among the studies by Egger's test. The funnel figure of these studies showed a symmetrical inverted distribution that was consistent with the results of Egger's test (online supplementary figure S2).

\section{DISCUSSION}

In this study, we carried out the accumulated evidence to explore the relationship between air pollutants and GDM from observational studies. Results indicated that exposure to $\mathrm{PM}_{2.5}$ in the second trimester, and exposures to $\mathrm{SO}_{2}, \mathrm{NO}_{2}$ and $\mathrm{NO}_{\mathrm{x}}$ were significantly associated with the increased risk of GDM.

In the current analysis, the relationship of $\mathrm{PM}_{2.5}$ and risk of GDM was observed only in the second trimester, but not in the pre-pregnancy or the first trimester. This is consistent with the results of a prior study that suggested $\mathrm{PM}_{25}$ may affect glucose homeostasis only during the second trimester of pregnancy. ${ }^{23}$ Additionally, Fleisch et $a l^{13}$ found that women with the highest quartile exposure (12.8$15.9 \mu \mathrm{g} / \mathrm{m}^{3}$ ) to $\mathrm{PM}_{2.5}$ during the second trimester had a 2.63 (95\% CI 1.15 to 6.01 ) times higher risk of having impaired glucose tolerance (IGT) than the women who had first quartile exposure. In another study, Fleisch $e t \mathrm{al}^{14}$ noted that women younger than 20 years had 1.36 higher odds of GDM (95\% CI 1.08 to 1.70) for each interquartile increment in $\mathrm{PM}_{2.5}$ exposure than the older women, at the second trimester. $\mathrm{O}_{3}$ was the other air pollutant that showed significant association with GDM in our analysis, consistent with Robledo $e t a l^{20}$ who found significant associations of GDM with interquartile increment in the preconception (5.37 ppb) and the first trimester (3.31 ppb) periods, with ORs of 1.05 (95\% CI 1.01 to 1.09) and 1.04 (95\% CI 1.01 to 1.08). A previous study noted increased risks of GDM in relation to nitric oxide exposures ${ }^{18}$ while our study documented a significant association between $\mathrm{NO}_{2}$ and $\mathrm{NO}_{\mathrm{x}}$ exposure with the risk of GDM.

The possible mechanisms underlying the associations between air pollutants and GDM are still unclear. Several different aspects were raised by many researchers based on their opinions, including inflammation (adipose tissue inflammation, ${ }^{31}$ peripheral inflammation, ${ }^{32}$ systemic inflammation which is indicated by elevated serum C-reactive protein $^{33}$ and cytokines ${ }^{34}$ ), oxidative damage, ${ }^{35}$ direct endothelial dysfunction, ${ }^{36}$ and dyslipidemia. ${ }^{37}$
$\mathrm{PM}_{2.5}$ was considered to initiate toxic effects and stimulate the production of free radicals or reactive oxygen. ${ }^{38}$ Levels of oxidative stress biomarkers, glutathione peroxidase and malonic dialdehyde, for instance, vary after $\mathrm{PM}_{2.5}$ exposure. ${ }^{39}{ }^{40}$ Moreover, $\mathrm{PM}_{2.5}$ exposure during pregnancy can downregulate the expression of glucose transporter 2 in pancreatic $\beta$-cells and thereby yield glucose intolerance in GDM rats. ${ }^{41}$ Similarly, possible mechanisms linking insulin resistance with exposure to $\mathrm{PM}_{2.5}$ have been demonstrated by several human studies and are recognized as one of the important underlying metabolic conditions contributing to the development of GDM. ${ }^{42}$ The observation that $\mathrm{O}_{3}$-induced insulin resistance was associated with neuronal activation and sympathetic stimulation has been found by Bass $e t a l^{43}$ The other opinion shows that $\mathrm{O}_{3}$ may damage the $\beta$-cells of the pancreas, according to which $\mathrm{O}_{3}$ is known to alter T-cell-dependent immune response, ${ }^{44}$ leading to the reduced insulin secretion. ${ }^{45}$ For the $\mathrm{SO}_{2}$, studies also showed similar mechanisms, such as inflammation ${ }^{46}$ and dysfunction of pancreatic $\beta$-cells. ${ }^{47}$ It has been argued that $\mathrm{NO}_{2}$ and $\mathrm{NO}_{\mathbf{x}}$ can lead similar inflammation responses to those of particulate matter and $\mathrm{O}_{3}{ }^{48}$

The strengths of our study included the adjustment for multiple confounders including geographic, sex, BMI, smoking, alcohol consumption, socioeconomic status, and age variables that affected the individual studies, but were reduced by our study design. Further, our meta-analysis is the most recent that comprehensively, critically, and quantitatively assesses the association between air pollutants and gestational diabetes.

Our study had the following limitations. (1) All included studies were observational studies, thus, the causal effect between air pollutants and GDM could not be described. (2) The high heterogeneity identified for some of the pollutants may be due to differences in race, blood glucose measurement, and pollutant concentrations in different regions. (3) This article analyzed respectively the relationship between eight different air pollutants $\left(\mathrm{PM}_{2.5}, \mathrm{O}_{3}, \mathrm{SO}_{2}, \mathrm{NO}_{2}, \mathrm{NO}_{\mathrm{x}}, \mathrm{CO}\right.$, $\mathrm{PM}_{10}$, and $\mathrm{BC}$ ) with GDM. Besides these eight kinds of air pollutants, there are also some other pollutants that may influence the risk of GDM. ${ }^{18}$ (4) In our daily life, different kinds of air pollutants are mixed and it is impossible to distinguish them from each other. The influence of the mixed air pollutants could not be analyzed because of the diversity of methods that researchers chose in individual studies. (5) Most studies were performed during the first and second trimesters, however, only few studies were performed before the conception. It was thus difficult to perform analyses during the preconception stage. (6) In addition to concentration of outdoor air pollutants, the distance from the main traffic road and noise, active and passive smoking are also potential risk factors for GDM. However, because of the scope of our study and the differences in measuring ways and indicators, we were unable to study these variables.

\section{PROSPECTS AND CONCLUSION}

Future studies may focus on the relationship between exposure to different air pollutants before conception 
and GDM. The relationship between some other outdoor air pollutants, such as sulfur oxide, and GDM needs to be analyzed, and a dose-response manner should be of important consideration while analyzing the association of air pollutants with the risk of GDM. The effect of different combinations of air pollutants also needs to be studied more systematically. In addition, the distance from the main traffic road and noise are also potential risk factors for GDM, ${ }^{49}$ so as passive smoking during the pregnancy. ${ }^{50}$ Thus, further exploration for the effect of these factors is needed to help develop more accurate prevention strategies.

To sum up, the available evidence indicated direct association of air pollutants and GDM risk. High-quality and longitudinal studies are needed to improve our understanding of this association.

Acknowledgements Authors are solely responsible for the design and conduct of this study; all study analyses, the drafting and editing of the manuscript, and its final contents.

Contributors The authors are solely responsible for the design and conduct of this study; all study analyses, the drafting and editing of the manuscript, and its final contents. XT and J-BZ contributed to the interpretation of data, and drafting the report. XT, FL, and YiH contributed to the data collection, statistical analysis and drafting the report. MAC and YoH made revisions. J-BZ and LQ contributed to study design and review.

Funding This work was supported by the National Science Foundation Council of China (81870556, 81670738), the Beijing Municipal Administration of Hospital's Youth Programme (QML20170204), and the Excellent Talents in Dongcheng District of Beijing (2018019).

Competing interests None declared.

Patient consent for publication Not required.

Provenance and peer review Not commissioned; externally peer reviewed.

Data availability statement All data relevant to the study are included in the article or uploaded as supplementary information.

Open access This is an open access article distributed in accordance with the Creative Commons Attribution 4.0 Unported (CC BY 4.0) license, which permits others to copy, redistribute, remix, transform and build upon this work for any purpose, provided the original work is properly cited, a link to the licence is given, and indication of whether changes were made. See: https://creativecommons.org/ licenses/by/4.0/.

ORCID iD

Jian-Bo Zhou http://orcid.org/0000-0003-2507-9192

\section{REFERENCES}

1 Kar P, Holt RIG. The effect of sulphonylureas on the microvascular and macrovascular complications of diabetes. Cardiovasc Drugs Ther 2008;22:207-13.

2 American Diabetes Association. Diagnosis and classification of diabetes mellitus. Diabetes Care 2014;37 Suppl 1:S81-90.

3 Galtier F. Definition, epidemiology, risk factors. Diabetes Metab 2010;36:628-51.

4 Inocêncio G, Braga A, Lima T, et al. Which factors influence the type of delivery and cesarean section rate in women with gestational diabetes? J Reprod Med 2015;60:529-34.

5 Beelen R, Raaschou-Nielsen O, Stafoggia M, et al. Effects of longterm exposure to air pollution on natural-cause mortality: an analysis of 22 European cohorts within the multicentre escape project. Lancet 2014:383:785-95.

6 Chuang K-J, Yan Y-H, Chiu S-Y, et al. Long-Term air pollution exposure and risk factors for cardiovascular diseases among the elderly in Taiwan. Occup Environ Med 2011;68:64-8.

7 Tamayo T, Rathmann W, Krämer U, et al. Is particle pollution in outdoor air associated with metabolic control in type 2 diabetes? PLoS One 2014;9:e91639.
8 Whitsel EA, Quibrera PM, Christ SL, et al. Heart rate variability, ambient particulate matter air pollution, and glucose homeostasis: the environmental epidemiology of arrhythmogenesis in the women's health Initiative. Am J Epidemiol 2009;169:693-703.

9 Eze IC, Hemkens LG, Bucher HC, et al. Association between ambient air pollution and diabetes mellitus in Europe and North America: systematic review and meta-analysis. Environ Health Perspect 2015;123:381-9.

10 Riant M, Meirhaeghe A, Giovannelli J, et al. Associations between long-term exposure to air pollution, glycosylated hemoglobin, fasting blood glucose and diabetes mellitus in northern France. Environ Int 2018:120:121-9.

11 Ben-Haroush A, Yogev Y, Hod M. Epidemiology of gestational diabetes mellitus and its association with type 2 diabetes. Diabet Med 2004;21:103-13.

12 Choe S-A, Kauderer S, Eliot MN, et al. Air pollution, land use, and complications of pregnancy. Sci Total Environ 2018;645:1057-64.

13 Fleisch AF, Gold DR, Rifas-Shiman SL, et al. Air pollution exposure and abnormal glucose tolerance during pregnancy: the project VIVA cohort. Environ Health Perspect 2014;122:378-83.

14 Fleisch AF, Kloog I, Luttmann-Gibson H, et al. Air pollution exposure and gestational diabetes mellitus among pregnant women in Massachusetts: a cohort study. Environ Health 2016;15:40.

$15 \mathrm{Hu} \mathrm{H}, \mathrm{Ha} \mathrm{S}$, Henderson BH, et al. Association of atmospheric particulate matter and ozone with gestational diabetes mellitus. Environ Health Perspect 2015;123:853-9.

16 Lu M-C, Wang P, Cheng T-J, et al. Association of temporal distribution of fine particulate matter with glucose homeostasis during pregnancy in women of Chiayi City, Taiwan. Environ Res 2017;152:81-7.

17 Malmqvist E, Jakobsson K, Tinnerberg H, et al. Gestational diabetes and preeclampsia in association with air pollution at levels below current air quality guidelines. Environ Health Perspect 2013;121:488-93.

18 Pan S-C, Huang C-C, Lin S-J, et al. Gestational diabetes mellitus was related to ambient air pollutant nitric oxide during early gestation. Environ Res 2017;158:318-23.

19 Pedersen M, Olsen SF, Halldorsson TI, et al. Gestational diabetes mellitus and exposure to ambient air pollution and road traffic noise: a cohort study. Environ Int 2017;108:253-60.

20 Robledo CA, Mendola P, Yeung E, et al. Preconception and early pregnancy air pollution exposures and risk of gestational diabetes mellitus. Environ Res 2015;137:316-22.

21 Shen H-N, Hua S-Y, Chiu C-T, et al. Maternal exposure to air pollutants and risk of gestational diabetes mellitus in Taiwan. Int $\mathrm{J}$ Environ Res Public Health 2017;14:1604.

22 van den Hooven EH, Jaddoe VWV, de Kluizenaar Y, et al. Residential traffic exposure and pregnancy-related outcomes: a prospective birth cohort study. Environ Health 2009;8:59.

23 Choe S-A, Eliot MN, Savitz DA, et al. Ambient air pollution during pregnancy and risk of gestational diabetes in New York City. Environ Res 2019;175:414-20.

24 Jo H, Eckel SP, Chen J-C, et al. Associations of gestational diabetes mellitus with residential air pollution exposure in a large southern California pregnancy cohort. Environ Int 2019;130:104933.

25 Stroup DF, Berlin JA, Morton SC, et al. Meta-Analysis of observational studies in epidemiology: a proposal for reporting. meta-analysis of observational studies in epidemiology (moose) group. JAMA 2000;283:2008-12.

26 Moher D, Liberati A, Tetzlaff J, et al. Preferred reporting items for systematic reviews and meta-analyses: the PRISMA statement. PLoS Med 2009;6:e1000097.

27 Mishra S, Bhadoria AS, Kishore S, et al. Gestational diabetes mellitus 2018 guidelines: an update. J Family Med Prim Care 2018:7:1169-72.

28 Stang A. Critical evaluation of the Newcastle-Ottawa scale for the assessment of the quality of nonrandomized studies in metaanalyses. Eur J Epidemiol 2010;25:603-5.

29 Egger M, Davey Smith G, Schneider M, et al. Bias in meta-analysis detected by a simple, graphical test. BMJ 1997;315:629-34.

30 Bobrovitz N, Onakpoya I, Roberts N, et al. Protocol for an overview of systematic reviews of interventions to reduce unscheduled hospital admissions among adults. BMJ Open 2015;5:e008269.

31 Andersen ZJ, Raaschou-Nielsen O, Ketzel M, et al. Diabetes incidence and long-term exposure to air pollution: a cohort study. Diabetes Care 2012;35:92-8.

32 Liu C, Ying Z, Harkema J, et al. Epidemiological and experimental links between air pollution and type 2 diabetes. Toxicol Pathol 2013;41:361-73

33 Rich DQ, Kipen HM, Huang W, et al. Association between changes in air pollution levels during the Beijing Olympics and biomarkers 
of inflammation and thrombosis in healthy young adults. JAMA 2012;307:2068-78.

34 Shoelson SE, Lee J, Goldfine AB. Inflammation and insulin resistance. J Clin Invest 2006;116:1793-801.

35 Sun Y, Taguchi K, Sumi D, et al. Inhibition of endothelial nitric oxide synthase activity and suppression of endothelium-dependent vasorelaxation by 1,2-naphthoquinone, a component of diesel exhaust particles. Arch Toxicol 2006;80:280-5.

36 Rao X, Montresor-Lopez J, Puett R, et al. Ambient air pollution: an emerging risk factor for diabetes mellitus. Curr Diab Rep 2015; 15:603.

37 Chuang K-J, Yan Y-H, Cheng T-J. Effect of air pollution on blood pressure, blood lipids, and blood sugar: a population-based approach. J Occup Environ Med 2010;52:258-62.

38 Upadhyay D, Panduri V, Ghio A, et al. Particulate matter induces alveolar epithelial cell DNA damage and apoptosis: role of free radicals and the mitochondria. Am J Respir Cell Mol Biol 2003;29:180-7.

39 Luo B, Shi H, Wang L, et al. Rat lung response to PM2.5 exposure under different cold stresses. Int $J$ Environ Res Public Health 2014;11:12915-26.

40 Araujo JA, Barajas B, Kleinman M, et al. Ambient particulate pollutants in the ultrafine range promote early atherosclerosis and systemic oxidative stress. Circ Res 2008;102:589-96.

41 Yi L, Wei C, Fan W. Fine-particulate matter (PM2.5), a risk factor for rat gestational diabetes with altered blood glucose and pancreatic GLUT2 expression. Gynecol Endocrinol 2017;33:611-6.

42 Brook RD, Xu X, Bard RL, et al. Reduced metabolic insulin sensitivity following sub-acute exposures to low levels of ambient fine particulate matter air pollution. Sci Total Environ 2013;448:66-71.
43 Bass V, Gordon CJ, Jarema KA, et al. Ozone induces glucose intolerance and systemic metabolic effects in young and aged brown Norway rats. Toxicol Appl Pharmacol 2013;273:551-60.

44 Krishna MT, Madden J, Teran LM, et al. Effects of 0.2 PPM ozone on biomarkers of inflammation in bronchoalveolar lavage fluid and bronchial mucosa of healthy subjects. Eur Respir $J$ 1998:11:1294-300.

45 Kelishadi R, Mirghaffari N, Poursafa P, et al. Lifestyle and environmental factors associated with inflammation, oxidative stress and insulin resistance in children. Atherosclerosis 2009;203:311-9.

46 Lee $\mathrm{H}$, Myung W, Jeong B-H, et al. Short- and long-term exposure to ambient air pollution and circulating biomarkers of inflammation in non-smokers: a hospital-based cohort study in South Korea. Environ Int 2018;119:264-73.

47 Yang B-Y, Qian ZM, Li S, et al. Ambient air pollution in relation to diabetes and glucose-homoeostasis markers in China: a crosssectional study with findings from the 33 communities Chinese Health study. Lancet Planet Health 2018;2:e64-73.

48 Hesterberg TW, Bunn WB, McClellan RO, et al. Critical review of the human data on short-term nitrogen dioxide (NO2) exposures: evidence for NO2 no-effect levels. Crit Rev Toxicol 2009;39:743-81.

49 Cappuccio FP, D'Elia L, Strazzullo P, et al. Quantity and quality of sleep and incidence of type 2 diabetes: a systematic review and meta-analysis. Diabetes Care 2010;33:414-20.

50 Cupul-Uicab LA, Skjaerven R, Haug K, et al. In utero exposure to maternal tobacco smoke and subsequent obesity, hypertension, and gestational diabetes among women in the MobA cohort. Environ Health Perspect 2012;120:355-60. 